\title{
Agronomic behavior of grape rootstocks resistant to young vine decline in Santa Catarina State, Brazil
}

\author{
Marco Dalbó $^{1, \text { a }}$ and Nelson Feldberg ${ }^{2}$ \\ ${ }^{1}$ Epagri, Videira Experiment Station, C.P. 21, 89560-000 Videira, SC, Brazil \\ ${ }^{2}$ Embrapa Products and Market, C.P. 317, 89460-000 Canoinhas, SC, Brazil
}

\begin{abstract}
Young vine decline, caused by the ground pearl or margarodes (Eurhizococcus brasiliensis) and pathogenic fungi (Cylindrocarpon, Phaeoacremonium and others), is a major problem in many vineyards of Southern Brazil. According to previous studies, the most resistant roostocks were hybrids of tropical species, such as Vitis caribaea (IAC 572, IAC 571-6, IAC 766) and V. cinerea (IAC 313). A medium resistance level was observed in V. champinii (Dog Ridge) and Muscadinia rotundifolia hybrids (VR 043-43). However, these rootstocks have not being used in grape growing areas of Southern Brazil. An experiment was carried out to evaluate the agronomic characteristics of the scion cultivar Moscato Embrapa grafted on these rootstocks compared to Paulsen 1103 and R99, considered standards for this region. The tropical rootstocks IAC 313, IAC571-6, and IAC 766 induced earlier bud break compared to Paulsen 1103, the opposite of VR043-43 and Dog Ridge. In general aspects, all rootstocks tested can be used for grape production. Even the tropical rootstocks with no winter dormancy behave as normal rootstocks when grafted. IAC 572 has an advantage of not inducing early bud break. However, excessive vigor is the most limiting factor for IAC 572, requiring especial management practices to control vegetative development.
\end{abstract}

\section{Introduction}

Grapevine rootstocks were developed primarily for resistance to phylloxera and other vine pests, as well as adaptation to different soil conditions [1]. In southern Brazil, the occurrence of young vine decline and dyeback has led the search for rootstocks that can solve also this problem, which is quite severe in some places. In the Rio do Peixe Valley, the largest wine region of Santa Catarina State, for example, it was a major factor which led to a significant reduction in the planted area in the 80 s and 90s [2].

The primary cause attributed to this syndrome is the Brazilian ground-pearl or margarodes (Eurhizococcus brasiliensis). It is a root scale that attacks a large variety of hosts but it is particularly harmful to grapevine [3]. However, there are evidences that the damage caused by ground-pearl in vine roots have led to infection by several species of pathogenic soil fungi, such as Cylindrocarpon, Phaeoacremonium and others [4]. The symptoms are similar to "young vine decline" and other grapevine diseases (Petri disease, esca) caused by this kind of fungi that were reported in other countries [5-7]. This situation requires rootstocks with a more complex form of resistance, due to the multiplicity of factors involved.

Field trials with rootstocks in areas with high incidence of vine decline have shown that the traditional rootstocks are highly susceptible [8]. Hybrids of tropical species (Vitis caribaea, V. cinerea) had the highest levels of resistance, whereas hybrid of Muscadinia rotundifolia (VR 043-43 and VR 039-16) and Dog Ridge (V. champinii) had

\footnotetext{
${ }^{a}$ Corresponding author: dalbo@epagri.sc.gov.br
}

intermediate resistance [8]. Hybrids of $V$. caribaea, such as IAC 572, were created for tropical regions, where it has superior performance in terms of productivity $[9,10]$ (Terra et al., 2001; Pauletto et al, 2001a.). In colder regions, as in the Midwest of Santa Catarina State, tropical characteristics are limiting factors to its use, such as damage by frost in young plants and induction of early bud break. They also tend to induce excessive vigour to the scion [11].

Considering that the rootstocks that showed greater resistance to vine decline are not used in the viticulture of southern Brazil, we have studied the agronomic performance of these materials compared to traditional rootstocks.

\section{Material and methods}

The experiment was installed on a private property in Videira, Santa Catarina State (altitude: $855 \mathrm{~m}$ a.s.l., latitude: $26^{\circ} 56^{\prime} 09^{\prime} \mathrm{S}^{\prime}$, longitude: $\left.51^{\circ} 14^{\prime} 41^{\prime \prime} \mathrm{W}\right)$. The soil is classified as eutrophic haplic Cambisol [12].

Seven rootstocks were tested, two of them are commonly used in this region (Paulsen 1103 and R99) and the others chosen based on previous studies that indicated that some rootstocks had a lower incidence of vine decline. The following rootstocks were evaluated, with their origin (cross): Paulsen 1103 (V. berlandieri x V. rupestris); R99 (V. berlandieri $\mathrm{x} V$. rupestris); VR 043-43 (V. vinifera $\mathrm{x}$ Muscadinia rotundifolia); Dog Ridge ( $V$. champinii); IAC 313 (V. cinerea x Golia); IAC 572 (V. caribaea x 101-14); IAC 571-6 (V. vinifera x V. caribaea); IAC 766 (V. caribaea $\mathrm{x} 106-8)$. 
Table 1. Bud break date of the cultivar 'Moscato Embrapa' grafted over different rootstocks in four years of evaluation.

\begin{tabular}{lcccc}
\hline Rootstock & 2012 & 2013 & 2014 & 2015 \\
\hline VR 043-43 & Sep. 9 & Sep. 9 & Sep. 28 & Sep. 11 \\
Dog Ridge & Sep. 10 & Sep. 16 & Sep. 28 & Sep. 8 \\
IAC 313 & Sep. 3 & Sep. 8 & Sep. 25 & Sep. 3 \\
IAC 571-6 & Sep. 6 & Sep. 3 & Sep. 20 & Sep. 5 \\
IAC 572 & Sep. 6 & Sep. 12 & Sep. 25 & Sep. 9 \\
IAC 766 & Sep. 6 & Sep. 6 & Sep. 18 & Sep. 4 \\
Paulsen 1103 & Sep. 6 & Sep. 10 & Sep. 20 & Sep. 5 \\
R99 & Sep. 7 & Sep. 12 & Sep. 25 & Sep. 8
\end{tabular}

The rootstocks were planted in situ in 2009. They were grafted with the scion cultivar Moscato Embrapa in August 2010. In the following year, some grafts that had failed in the previous year were remade. Soil management consisted of wed control with herbicides along the rows and mowing in between lines. Periodically spraying with fungicides was also made to control fungal diseases of the aerial part.

For the evaluation of productivity and fruit quality, the initial yelds were discarded and considered only the data obtained in the harvests from 2014 to 2016 (4, 5 and 6 years after grafting), when the plant development was more uniform. Grape quality assessments were based on 100 berry samples collected randomly in the plot. The must was analysed for soluble solids ( ${ }^{\circ}$ Brix), and titratable acidity. The evaluation of phenological data (bud break time) was extended from 2012 to 2015. It was considered that the plants were beginning to sprout when most terminal buds reached the green tip stage.

The experimental design was a randomized block design with five replications. The plots consisted of four plants spaced $3.5 \times 1.5 \mathrm{~m}$. Statistical analysis (anova) was made using the software R. Since there were no cases of significant interaction year $\times$ rootstock, statistical analysis is presented for the average of all years of evaluation.

\section{Results and discussion}

The phenological observations made in four years of evaluation indicate that the rootstock has influence on the bud break time of the scion (Moscato Embrapa) and that these differences are maintained consistently over the years (Table 1). Considering the rootstock Paulsen 1103 as a reference, it was observed that some rootstocks, such as VR 043-43, Dog Ridge and R99 induced a later bud break. On the other hand, the rootstocks IAC 313, IAC 571-6 and IAC 766 tend to induce earlier bud break. These three rootstocks are hybrids of tropical species in which there is not a dormancy period, which could be leading to early budding of the scion. However, the IAC 572 also features tropical characteristics, but the bud break of the scion was relatively late, usually a few days after Paulsen 1103.

Late bud break is particularly advantageous in years with occurrence of late frosts, as it happened in the last year of evaluation (2015). In this year, the weather conditions were quite atypical, with a very mild winter, but with frosts on September 10 and 11, when all the plants had already started sprouting. Although there has been damage in all combinations scion-rootstocks, production losses in the harvest 2015-2016 were higher in the case of rootstocks that led to early budding (Table 2). In this season, the highest yields were provided by the rootstocks
Table 2. Productivity ( $\mathrm{T} \cdot \mathrm{ha}^{-1}$ ) of the cultivar 'Moscato Embrapa' grafted over different rootstocks in three years of evaluation.

\begin{tabular}{lcccc}
\hline Rootstock & $\mathbf{2 0 1 4}$ & $\mathbf{2 0 1 5}$ & $\mathbf{2 0 1 6}$ & Avg. \\
\hline & \multicolumn{5}{c}{ T.ha } \\
VR 043-43 & 25.3 & 25.8 & 14.2 & $21.8 \mathrm{a}^{\text {* }}$ \\
Dog Ridge & 17.1 & 19.0 & 8.8 & $15.0 \mathrm{bc}$ \\
IAC 313 & 14.0 & 17.5 & 6.2 & $12.5 \mathrm{c}$ \\
IAC 571-6 & 22.2 & 20.6 & 15.5 & $19.5 \mathrm{ab}$ \\
IAC 572 & 23.4 & 22.3 & 21.1 & $22.3 \mathrm{a}$ \\
IAC 766 & 20.8 & 16.5 & 8.3 & $15.2 \mathrm{bc}$ \\
Paulsen 1103 & 25.3 & 24.5 & 9.7 & $19.9 \mathrm{ab}$ \\
R99 & 16.6 & 15.2 & 6.6 & $12.8 \mathrm{c}$ \\
* Significant at 5\% level by Tukey test.
\end{tabular}

Table 3. Plant vigor (measured by winter pruning material) of the cultivar 'Moscato Embrapa' grafted over different rootstocks in two years of evaluation.

\begin{tabular}{lccc}
\hline Rootstock & $\mathbf{2 0 1 4}$ & $\mathbf{2 0 1 5}$ & Avg. \\
\hline & \multicolumn{3}{c}{${\mathrm{Kg} \cdot \text { plant }^{-1}}$} \\
VR 043-43 & 2.26 & 1.38 & $1.82 \mathrm{~cd}^{*}$ \\
Dog Ridge & 2.08 & 1.49 & $1.78 \mathrm{~cd}$ \\
IAC 313 & 2.59 & 1.88 & $2.24 \mathrm{bc}$ \\
IAC 571-6 & 2.96 & 2.11 & $2.53 \mathrm{~b}$ \\
IAC 572 & 4.23 & 3.08 & $3.65 \mathrm{a}$ \\
IAC 766 & 2.44 & 2.09 & $2.26 \mathrm{bc}$ \\
Paulsen 1103 & 2.30 & 1.57 & $1.93 \mathrm{bcd}$ \\
R99 & 2.11 & 0.95 & $1.53 \mathrm{~d}$ \\
\hline
\end{tabular}

* Significant at $5 \%$ level by Tukey test.

IAC 572 and VR 043-43, probably resulting from a combination of later and more vigorously sprouting, which resulted in a greater recovery of the productive capacity of the plants after the damage caused by frosts. In the previous two years, when climatic conditions were normal, the productivity differences between the rootstocks were lower, and only in 2014 there were significant differences. The rootstocks IAC 313 and R99 were those which resulted in lower productivity. In the case of R99, it is possibly associated with lower plant vigor (Table 3 ).

IAC 572 was the rootstock that induced the highest vigor to the scion and the R99, the less vigorous. The others have shown intermediate results (Table 3). The evaluation of plant vigor, measured by weight of material removed in the winter pruning, was made only in two seasons but the results were quite consistent. The high vigor of the canopy induced by IAC series rootstocks, particularly by IAC 572 , had already been observed in other studies [11]. In the present experiment, for the IAC 572 plots, it was necessary three green pruning interventions to control vegetative growth.

Excessive plant growth induced by IAC 572 seems to be the main negative factor of this rootstock, although it was not an impediment. A tendency to occur floral abortion was eventually observed in some plants with this rootstock, but did not affect grape production.

Based on the variables used to assess fruit quality, it was not observed consistent differences between rootstocks over the years. For example, R99 has resulted in lower acidity levels (Table 5), but it was not among the rootstocks that provided higher soluble solids content (Table 4). IAC 572 resulted in lower soluble solid content (Table 4). However, highly vigorous scion/ rootstock 
Table 4. Soluble solids content $\left({ }^{\circ}\right.$ Brix) of grape must of the cultivar 'Moscato Embrapa' grafted over different rootstocks in three years of evaluation.

\begin{tabular}{lcccc}
\hline Rootstock & $\mathbf{2 0 1 4}$ & $\mathbf{2 0 1 5}$ & $\mathbf{2 0 1 6}$ & Avg. \\
\hline & & ${ }^{\circ}$ Brix & & \\
VR 043-43 & 19.0 & 16.2 & 18.3 & $17.8 \mathrm{ab} *$ \\
Dog Ridge & 18.8 & 16.7 & 17.9 & $17.8 \mathrm{ab}$ \\
IAC 313 & 18.9 & 16.2 & 18.3 & $17.8 \mathrm{ab}$ \\
IAC 571-6 & 19.2 & 16.6 & 17.3 & $17,7 \mathrm{ab}$ \\
IAC 572 & 18.4 & 15.4 & 17.3 & $17.0 \mathrm{~b}$ \\
IAC 766 & 19.8 & 16.8 & 18.2 & $18.3 \mathrm{a}$ \\
Paulsen 1103 & 18.7 & 16.3 & 18.4 & $17.8 \mathrm{ab}$ \\
R99 & 18.3 & 16.7 & 17.8 & $17.6 \mathrm{ab}$ \\
\hline
\end{tabular}

* Significant at $5 \%$ level by Tukey test.

Table 5. Total acidity of grape must of the cultivar 'Moscato Embrapa' grafted over different rootstocks in three years of evaluation.

\begin{tabular}{lcccc}
\hline Rootstock & $\mathbf{2 0 1 4}$ & $\mathbf{2 0 1 5}$ & $\mathbf{2 0 1 6}$ & Avg. \\
\hline VR 043-43 & 70.3 & 76.9 & 84.8 & $77.3 \mathrm{ab}^{*}$ \\
Dog Ridge & 65.6 & 78.8 & 83,2 & $75.9 \mathrm{ab}$ \\
IAC 313 & 65.8 & 74.8 & 84.7 & $75.8 \mathrm{ab}$ \\
IAC 571-6 & 60.4 & 77.6 & 82.4 & $73.5 \mathrm{~b}$ \\
IAC 572 & 71.3 & 78.2 & 93.9 & $81.1 \mathrm{a}$ \\
IAC 766 & 64.6 & 81.2 & 87,2 & $77,7 \mathrm{ab}$ \\
Paulsen 1103 & 63.5 & 73.4 & 89.9 & $75.6 \mathrm{ab}$ \\
R99 & 52.0 & 66.9 & 74.8 & $64.5 \mathrm{c}$ \\
\hline * Significant at 5\% level by Tukey test.
\end{tabular}

combinations often result in longer vegetative cycle and take longer to reach maturity. In this experiment, the harvest time was the same for all rootstocks, which was unfavourable to IAC 572. So, it is not possible to highlight a rootstock that induces better qualitative characteristics in the scion production.

Overall, according to the data collected up to now, it is possible to use rootstocks with tropical characteristics, such as the IAC series, in cold regions of southern Brazil. IAC 572 stands out because it does not anticipate the bud break of the scion compared to the reference rootstock for this region (Paulsen 1103). It has provided the highest average level of productivity over the years, along with VR 043-43 and Paulsen 1103. IAC 572 was also one of the most resistant to decline and dyeback of young grapevine plants in previous works $[8,13]$. However, its main drawback is the high vigor induced to the scion, which requires management practices to reduce the vegetative growth, such as intensive green prunings and larger spacings between plants. It may be indicated for replanting areas, mainly for table grape cultivars or for grape juice production, where high vigor is more tolerated. For wine production, however, excessive vigor is a difficult defect to be bypassed with cultural practices, which requires the development of new rootstocks that are at the same time resistant and less vigorous.

\section{Conclusions}

In general aspects, all rootstocks tested can be used for grape production. Even the tropical rootstocks with no winter dormancy behave as normal rootstocks when grafted. Most of them induced earlier bud break of the scion but, in the case of IAC 572, it was the opposite. Excessive vigor is the most limiting factor for commercial use of vine decline rootstocks, especially for IAC 572, requiring especial management practices to control vegetative development.

\section{References}

[1] B.I. Reisch, C.L. Owens, P.S. Cousins, Grape. In: M.L. Badenes, D.H. Byrne, (ed.) Fruit Breeding, (Springer, New York, 2012)

[2] E. Schuck, M.A. Dalbó, J.P. Rosier, J.P. Ducroquet, Porta-enxertos para a cultura da Videira. In: IV Enfrute, Fraiburgo, SC. Anais. Caçador-SC, Epagri, p. 122-132, 2001 (2001)

[3] M. Botton, E.R. Hickel, S.J. Soria, I. Teixeira, Bento Gonçalves, RS: Embrapa Uva e Vinho, (Circular Técnica, 27). ISSN, 1516-5914 (2000)

[4] L.R. Garrido, O.R. Sonego, A.F. Urben, Fitopatologia Brasileira, 19:548-550 (2004)

[5] D. Gramaje, J. Armengol, Plant Disease 95: 1040-1055 (2011).

[6] M. Gatica, C. Césari, S. Magnin, J. Dupont, Phytopath. Mediterr., 40:S 317-324 (2001)

[7] J.A.Stamp, Phytopath. Mediterr., 40:S369-375 (2001)

[8] M.A. Dalbó, C.J. Arioli, R.N. Dambrós, Jornal da Fruta, 21:12-13 (2013)

[9] M.M. Terra, C.V. Pommer, E.J.P. Pires, I.J.A. Ribeiro, P.B. Gallo, I.R.S. Passos, Rev. Bras. Frutic., 23:382-386 (2001)

[10] D. Pauletto, F.A.A. Mourão Filho, R.A. Kluge, R.A. Scarpare Filho, Pesq. Agropec. Bras., 35:115-121 (2001)

[11] M.A. Dalbó, E. Schuck, C. Basso, Rev. Bras. Frutic., 33:941-947 (2011)

[12] EMBRAPA. Solos do Estado de Santa Catarina (Rio de Janeiro, Embrapa Solos - CNPS, 2004)

[13] A.L. Lourenção, M.M. Terra, E.J.P. Pires, E.J.P.; Pommer, C.V.; G.M.V. Ambrosano, Revista de Agricultura, 77:57-64 (2002) 